\title{
4-Vinylpyridine-Ethylene Glycol Dimethacrylate Copolymers. Formation of Porous Structure by Using Cyclohexanone and Toluene as Diluents in Suspension Polymerization
}

\author{
Muhammad Abdul Hamid, Riffat NaheEd, and Muhammad FuZail \\ Applied Chemistry Division, Pakistan Institute of Nuclear Science and Technology, \\ P.O. Nilore, Islamabad, Pakistan
}

(Received April 30, 1996)

\begin{abstract}
A series of porous copolymer beads were synthesized by suspension copolymerization of 4-vinylpyridine (4VP) with ethylene glycol dimethacrylate (EGDM) in the presence of diluents, cyclohexanone (CHN), and toluene (TOL). The resulting copolymer beads were characterized for their density, porosity, surface area, mechanical strength, and $\mathrm{Cl}^{-}$ion capacity. It was observed that the apparent density of the copolymer beads decreases with the decrease in $\mathrm{CHN}$ of a given mixture of diluents, $\%$ cross-linking agent $\left(\right.$ EGDM) and with the increase in solvent fraction $\left(F_{\mathrm{s}}\right)$. It was also observed that the porosity and surface area of the copolymer beads increase with the decrease in $\mathrm{CHN}$ of a given mixture of diluents, \% cross-linking agent and with the increase in solvent fraction. The mechanical strength of the copolymer beads decreases with the increase in solvent fraction. The $\mathrm{Cl}^{-}$ions capacity of the copolymer beads decreases with the increase in \% cross-linking agent whereas it is almost independent of the change of one component of a given mixture of diluents and solvent fraction.

KEY WORDS 4-Vinylpyridine-Ethylene Glycol Dimethacrylate Copolymers / Porous Structure /

Diluents / Solvent Fraction / Suspension Polymerization / Porosity / Surface Area / Mechanical Strength /

Copolymer Beads / Pore Size Distribution Curve /
\end{abstract}

It has been reported in the literature ${ }^{1,2}$ that anionexchange resin of hydrophilic nature can be synthesized by the copolymerization of 4-vinylpyridine with ethylene glycol dimethacrylate. Such hydrophilic resins have been used with certain advantages over the hydrophobic resins (4-vinylpyridine-divinylbenzene) for the separation of proteins particularly the serum albumin components.

Sugii et al. ${ }^{1}$ pointed out that although 4VP-divinylbenzene (DVB) has a larger pore diameter $(27.5 \mathrm{~nm}$ pore radius) than $4 \mathrm{VP}-\mathrm{EGDM}(8.7 \mathrm{~nm}$ pore radius) in the dry state, the exclusion limits of both resins were similar ( $\cong 500$ daltons) and small. These results have been explained on the basis of their findings that the pore volumes of the resins in the wet state were $0.38 \mathrm{ml} \mathrm{ml}^{-1}$ of $4 \mathrm{VP}-\mathrm{DVB}$ and $0.34 \mathrm{ml} \mathrm{m}^{-1}$ of $4 \mathrm{VP}-\mathrm{EGDM}$, i.e., nearly identical, indicating that the pore size distribution of both resins in the wet state is different from that in the dry state. Therefore, the 4VP-EGDM resin having a hydrophilic cross-linking structure is relatively more suitable anion-exchanger for the separation of proteins.

It has also been reported that the pore size of the resin markedly affects the resolution and recovery of proteins in reversed-phase chromatography ${ }^{3,4}$ and in ion-exchange chromatography. ${ }^{5-7}$ Ion exchange chromatography has the advantage that it can be carried out in an aqueous solution rather than in an organic solvent. Therefore, it is possible to prevent the denaturation of proteins caused by organic solvents. In the separation of proteins the use of ion-exchange resins of organic polymer matrix ${ }^{2,8-10}$ have certain advantages over surfacemodified silica gels such as chemical stability in alkaline solution, higher sample loading capacities, and longer column life.

In view of all the above mentioned facts, this work was undertaken to establish the most appropriate conditions to prepare the desired macroporous hydrophilic resins by the copolymerization of 4-vinylpyridine with ethylene glycol dimethacrylate in cyclohexanone and toluene diluents using the technique of suspension polymerization. In order to achieve this end the resins were prepared in a mixture of diluents with different percentage of solvating and non-solvating ratio, at different percentage of cross-linking agent and at different solvent fractions.

The characteristics of the resulting resins were determined with respect to their capacity, density, surface area, porosity, and mechanical strength in order to establish the most appropriate condition to synthesize resins suitable for a given separation work.

\section{EXPERIMENTAL}

\section{Material}

4-Vinylpyridine. 4-Vinylpyridine ( $96 \%$ pure) supplied by Merck, Germany was purified by fractional distillation under reduced pressure. The middle fraction about $75 \%$ of the starting material was collected and stored at $-5^{\circ} \mathrm{C}$ prior to its use in the polymerization experiments.

Ethylene Glycol Dimethacrylate. Ethylene glycol dimethacrylate (98\% pure) supplied by Merck, Germany was purified by fractional distillation under reduced pressure and the middle fraction about $80 \%$ of the starting material was collected and stored at $-5^{\circ} \mathrm{C}$ prior to its use in the polymerization experiments.

Benzoylperoxide, toluene, cyclohexanone, and other chemicals of technical grade, commercially available from Fluka Chemicals, Switzerland, were used as such without further purification.

\section{Synthesis of Copolymer}

Copolymer was synthesized by the reaction of DVB with EGDM using the technique of suspension polymerization. An organic phase consists of 4VP, EGDM, $\mathrm{CHN}$, and TOL of required amount whereas aqueous 
phase consists of gum arabic, gelatin ( $1.5 \%$ each of water) and $\mathrm{NaCl}$ ( $3 \%$ of water). Organic to aqueous phase ratio was $1: 5$. BPO $1 \%$ of the polymerization material was added to the organic phase before mixing the two phases. The two phases were then mixed and stirred at room temperature for half an hour under nitrogen atmosphere and then the temperature was raised to $80^{\circ} \mathrm{C}$. This process was continued for 24 hours. The resulting copolymer was washed successively with demineralized water (DMW), acetone and DMW. It was then sieved and certain fractions were collected, dried and used for their characterization.

The copolymer was converted into anion-exchange resin by treating it with hydrochloric acid if required.

\section{Characterization}

Capacity. The $\mathrm{Cl}^{-}$ions capacity of the copolymer was determined following a method similar to that described in the literature. ${ }^{11}$ The given air dried copolymer was weighed in two equal lots of $1 \mathrm{~g}$ each. One lot was dried in a vacuum oven at $80^{\circ} \mathrm{C}$ for 24 hours to determine its moisture contents whereas the other was loaded onto a column. The polymer bed thus made in the column was successively impregnated with $200 \mathrm{ml}$ of $0.1 \mathrm{~N} \mathrm{HCl}$ and $40 \mathrm{ml}$ of DMW (flow $2-3 \mathrm{ml} \mathrm{min}^{-1}$ ) and effluent was collected in a flask. The liquid retained in the voids of the particles was forced down under the pressure. The total volume of the effluent was then made upto $250 \mathrm{ml}$ by the addition of DMW. The concentration of $\mathrm{HCl}$ in the effluent was determined by a standard analytical method. The quantity of $\mathrm{HCl}$ consumed by the copolymer was considered as its capacity for $\mathrm{Cl}^{-}$ions.

Apparent Density. Apparent density of the copolymer was determined by measuring the volume and weight of its dry sample.

Porosity. The volume distribution of pores in copolymer beads was determined by using Micromeritics Porositymeter, Autopore-II 9220. It works on the principle of intrusion and extrusion of mercury vapors in the pores of a material at a given pressure.

Surface Area. Surface area of the copolymer beads was determined by using Brunaner-Emmett-Teller (BET) apparatus Model No. QS-11 Serial No. 1170 supplied by Quantachrome Corp. 6-Aerial Way, Syosset, N.Y. 11791, U.S.A. This technique works on the principle of adsorption and desorption of nitrogen gas in the pores of a material at a given temperature and pressure. Helium was used as carrier gas. The process of adsorption and desorption was monitored by measuring the change in the thermal conductivity of the gas as described in the BET method. ${ }^{12}$

Measurement of Mechanical Strength. The copolymer beads of a given size $(250 \mu \mathrm{m})$ was selected to measure its mechanical strength. The apparatus used to measure the mechanical strength was constructed in our laboratory, was very similar to the one described by Golden and Irving. ${ }^{13}$ In this technique the resin bead is subjected to compressive force which is monitored by a potentiometric chart recorder connected to the load cell output. Eventually the bead breaks, the pressure is released on the load cell platform, with the result that the recorder trace shows a peak whose height corresponds to the breaking load of the bead.

\section{RESULTS AND DISCUSSION}

\section{Effect of Diluents}

In order to synthesize macroporous copolymers of 4VP-EGDM a mixture of solvating and non-solvating diluents was used because it has already been establish$\mathrm{ed}^{14,15}$ that a certain combination of diluents results in a desired porous structure of copolymers. In this work therefore, a mixture of $\mathrm{CHN}$ (solvating diluent) and TOL (non-solvating diluent) was used to synthesize 4VPEGDM copolymers of desired porosity.

Two sets of polymerization experiments were carried out by varying the percentage ratio of diluents $\mathrm{CHN}$ : TOL from 100:0 to $0: 100$ while the other parameters were kept constant except that the cross-linking agent, EGDM was $30 \%$ and $50 \%$ in the first and second set of the experiments, respectively. The resulting copolymers were characterized for their bulk density, capacity, pore volume, and surface area. The results are summarized in Table I.

It was observed that bulk density of the copolymers decreases with the decrease in the percentage ratio of CHN from 100 to $0 \%$ or with the increase in TOL from 0 to $100 \%$ in the mixture of diluents at $30 \%$ and $50 \%$ cross-linking agent, EGDM, respectively (Table I). It can be seen from these results that the bulk density of a $50 \%$ cross-linked copolymer is slightly but consistently higher than $30 \%$ cross-linked copolymer at a given composition of diluents. It was also observed that the pore volume, $V_{\mathrm{p}}$ increases with the increase in the percentage composition of TOL (non solvating diluent) from 0 to $100 \%$ in the mixture of diluents (Table I). The values of $V_{\mathrm{p}}$ obtained for $30 \%$ and $50 \%$ cross-linked copolymers are almost identical in a given mixture of diluents. The results of bulk density and pore volume seems to be complimentary to one another that means the relatively porous structure results a relatively low density copolymer and vice versa.

The surface area determined for $30 \%$ and $50 \%$ crosslinked copolymer beads increases from 7 to $168 \mathrm{~m}^{2} \mathrm{~g}^{-1}$ and from 6.5 to $125 \mathrm{~m}^{2} \mathrm{~g}^{-1}$, respectively with the increase in the percentage ratio of TOL from 0 to $100 \%$ or decrease in $\mathrm{CHN}$ from 100 to $0 \%$ in the mixture of diluents. These results are complimentary to those of pore volume, hence it can be said that the increase in pore volume causes an increase in the surface area of the respective copolymer bead under the given experimental conditions.

Figure 1 shows the dependence of percentage pore volume on the pore diameter of $30 \%$ cross-linked copolymer beads synthesized in different percentage ratio of diluents (CHN, TOL). These curves, in actual fact represent the porosity of copolymer beads synthesized under the given experimental conditions.

The analysis of pore size distribution curves indicates that they are divided into three distinct groups. The curves of the copolymer beads synthesized in $\mathrm{CHN}$ and CHN : TOL (80:20) mixture are somewhat identical and the pore diameter of about $75 \%$ copolymer beads is less than $0.01 \mu \mathrm{m}$ whereas the curves of the copolymer beads synthesized in TOL and CHN : TOL $(20: 80)$ mixture are also identical and the pore diameter varies mainly from 0.1 to $1.0 \mu \mathrm{m}$. These results indicate that the small and 
Table I. Capacity, porosity, surface area, and density of the 4VP-EGDM Copolymers, synthesized using different ratio of solvating to non-solvating diluents ${ }^{\mathrm{a}}$

(Solvent fraction, $F_{\mathrm{s}}=0.5$ )

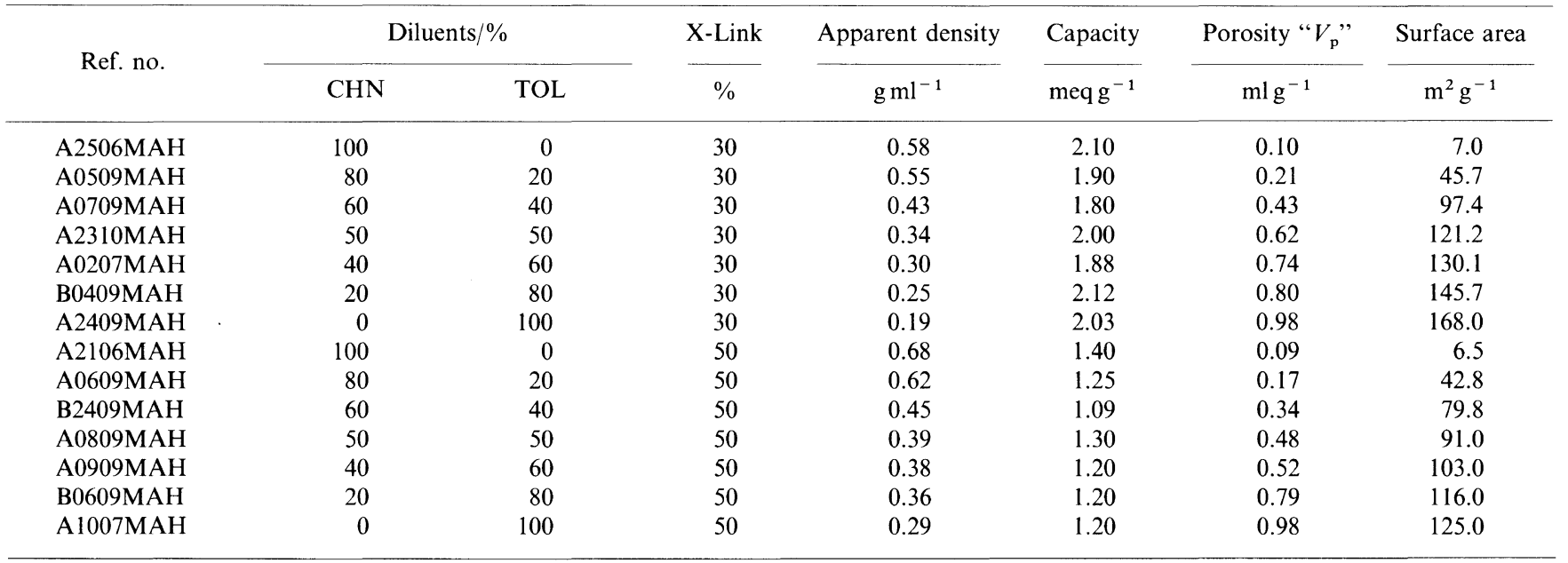

${ }^{a} 4 \mathrm{VP}=4$-vinylpyridine; $\mathrm{EGDM}=$ ethylene glycol dimethacrylate; $\mathrm{TOL}=$ toluene $\quad \mathrm{CHN}=$ cyclohexanone; $V_{\mathrm{p}}=$ pore volume; $F_{\mathrm{s}}=$ solvent fraction $=$ amount of diluents $/$ (amount of diluents + monomers); X-Link =EGDM.

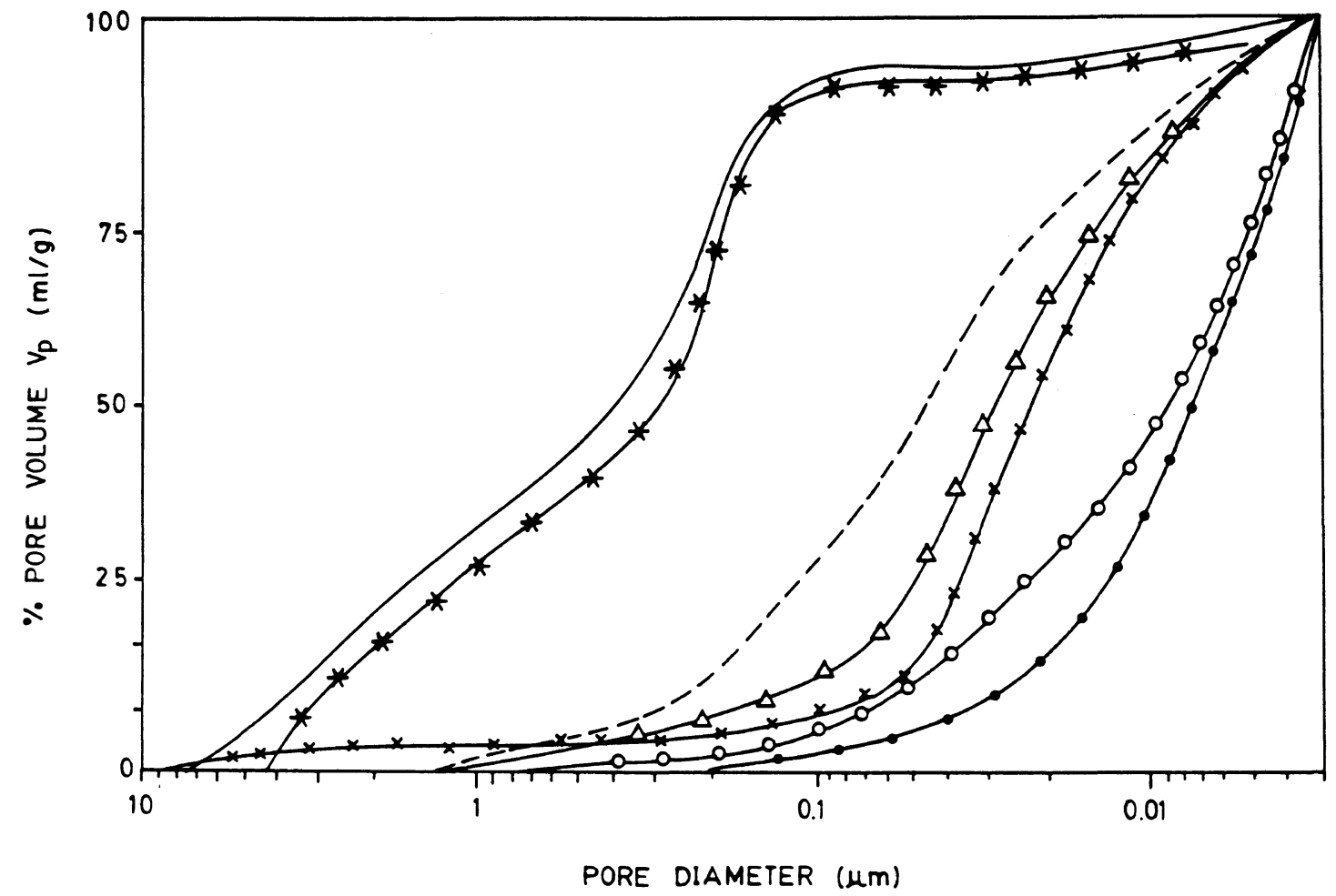

Figure 1. The dependence of pore volume $(\%)$ on pore diameter $(\mu \mathrm{m})$ of $4 \mathrm{VP}-\mathrm{EGDM}$ copolymer beads synthesized in different percentage ratio of diluents, CHN and TOL (pore size distribution curve). $\%$ CHN : \% TOL (cross-linkage $=30 \%$ ): $-, 0: 100 ;-*-*-*-, 20: 80 ;---, 40: 60$; $-\triangle-\triangle-\triangle-, 50: 50 ;-\times-\times-\times-, 60: 40 ;-\bigcirc-\bigcirc-\bigcirc-, 80: 20 ;-\bigcirc-\bigcirc-0-, 100: 0$.

large size pores are developed during the synthesis of copolymer beads in solvating $(\mathrm{CHN})$ and non solvating (TOL) diluents, respectively. A group of three curves representing the copolymer beads synthesized in $\mathrm{CHN}$ : TOL mixture of $60: 40,50: 50$, and $40: 60$ percentage ratio are similar to one another and the pore diameter varies mainly from 0.04 to $0.2 \mu \mathrm{m}$. These results indicate that the copolymer beads developed under the given experimental conditions reflect the best possible compromising combination of density, capacity, porosity, and surface area.

Figure 2 shows the pore size distribution curves of 1054
$50 \%$ cross-linked copolymer beads synthesized using the similar conditions as described above for $30 \%$ cross-linked copolymer beads. The analysis of these curves also support the above mentioned fact that the pore size distribution tends to shift toward larger pore size region with the increase in the TOL (non solvating solvent). This shift is not as marked as in the case of $30 \%$ cross-linked copolymer beads particularly when synthesized in $80 \%$ and $100 \%$ TOL. This is most probably due to the change in polarity of the system caused by the increase of EGDM which acts as a cross-linking agent as well as a solvating solvent. 


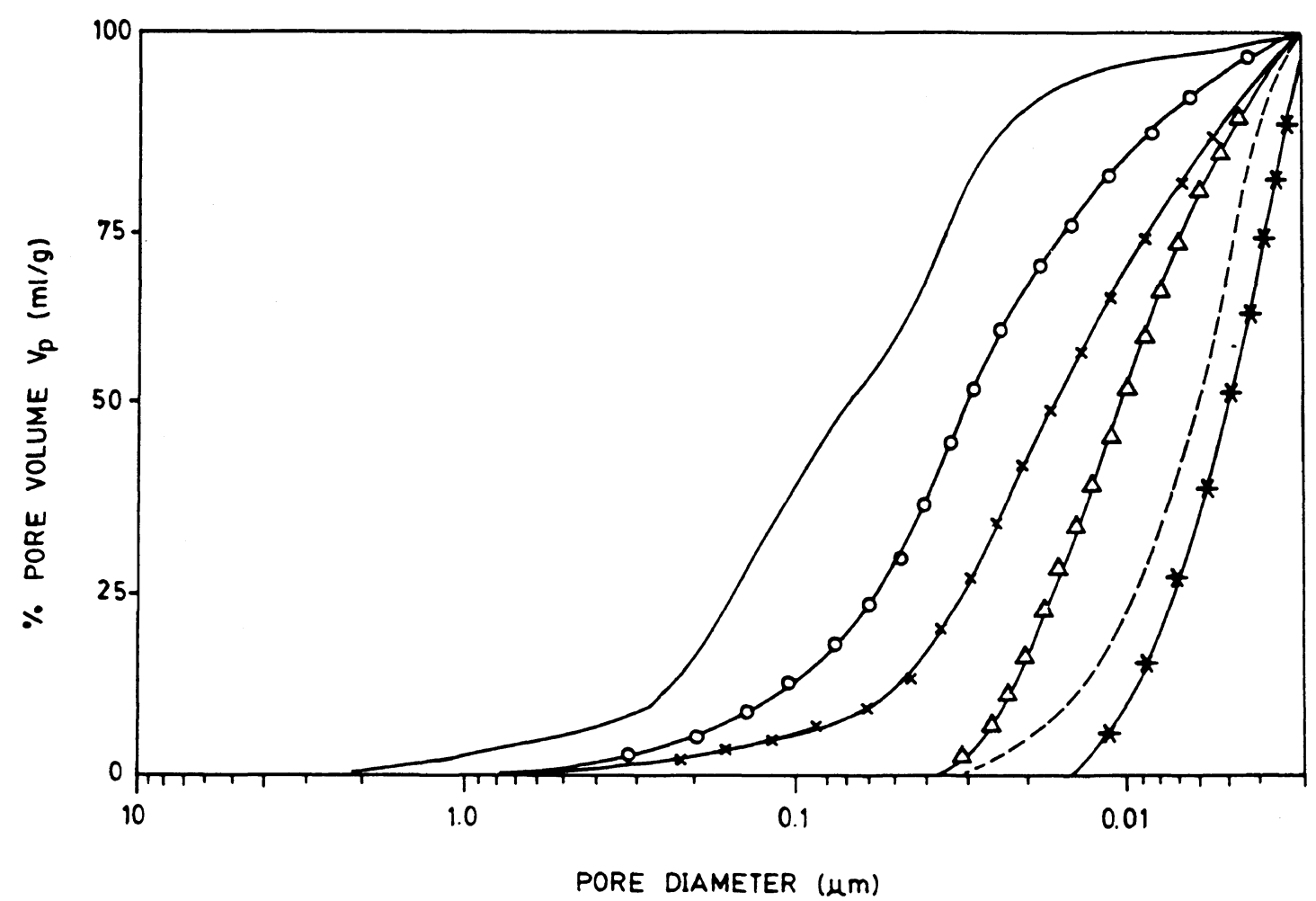

Figure 2. The dependence of pore volume $(\%)$ on pore diameter $(\mu \mathrm{m})$ of $4 \mathrm{VP}-\mathrm{EGDM}$ copolymer beads synthesized in different percentage ratio of diluents, CHN and TOL (pore size distribution curve). \% CHN:\% TOL (cross-linkage $=50 \%$ ): $-, 0: 100 ;-\mathrm{O}-\mathrm{O}-\mathrm{O}-, 20: 80$; $-\times-\times-\times-, 50: 50 ;-\triangle-\triangle-\triangle-, 60: 40 ;-\cdots, 80: 20 ;-*-*-*-, 100: 0$.

Table II. Capacity, porosity, surface area, density, and mechanical strength of

4VP-EGDM copolymers, synthesized using different amount of diluents ${ }^{\mathrm{a}}$

[Diluents, cyclohexanone : Toluene $(\mathrm{CHN}: \mathrm{TOL}=40: 60)]$

\begin{tabular}{|c|c|c|c|c|c|c|c|}
\hline \multirow{2}{*}{ Ref. no. } & \multirow{2}{*}{$F_{\mathrm{s}}$} & \multirow{2}{*}{$\frac{X \text {-Link }}{\%}$} & \multirow{2}{*}{$\frac{\text { Apparent density }}{\mathrm{g} \mathrm{ml}^{-1}}$} & \multirow{2}{*}{$\frac{\text { Capacity }}{\text { meq g }^{-1}}$} & \multirow{2}{*}{$\frac{\text { Porosity " } V_{\mathrm{p}} \text { ” }}{\mathrm{mlg}^{-1}}$} & \multirow{2}{*}{$\frac{\text { Surface area }}{\mathrm{m}^{2} \mathrm{~g}^{-1}}$} & \multirow{2}{*}{$\begin{array}{c}\text { Mech. strength* } \\
\text { " } L " \\
\text { Newtons }\end{array}$} \\
\hline & & & & & & & \\
\hline B2706MAH & 0.3 & 30 & 0.50 & 2.30 & - & 47.5 & 3.60 \\
\hline Buz07MAH & 0.4 & 30 & 0.40 & 2.15 & 0.49 & 114.0 & 1.50 \\
\hline A0207MAH & 0.5 & 30 & 0.30 & 1.88 & 0.74 & 130.0 & 0.82 \\
\hline B2806MAH & 0.6 & 30 & 0.28 & 2.42 & 0.96 & 146.2 & 0.62 \\
\hline A1809MAH & 0.7 & 30 & 0.16 & 2.25 & 1.92 & 209.0 & 0.17 \\
\hline B2706MAH & 0.8 & 30 & 0.13 & 2.39 & 3.08 & 235.1 & 0.05 \\
\hline В0307MAH & 0.3 & 50 & 0.53 & 1.01 & 0.17 & 11.2 & 4.65 \\
\hline В2009MAH & 0.4 & 50 & 0.51 & 0.96 & 0.37 & 85.5 & 2.20 \\
\hline A0809MAH & 0.5 & 50 & 0.38 & 1.20 & 0.52 & 103.0 & 1.60 \\
\hline B0507MAH & 0.6 & 50 & 0.34 & 1.07 & 0.96 & 124.6 & 1.10 \\
\hline A0307MAH & 0.7 & 50 & 0.25 & 1.08 & 1.17 & 130.3 & 0.80 \\
\hline B0407MAH & 0.8 & 50 & 0.22 & 1.03 & 1.73 & 150.4 & 0.55 \\
\hline
\end{tabular}

a $4 \mathrm{VP}=4$-vinylpyridine; $\mathrm{EGDM}=$ ethylene glycol dimethacrylate; TOL = toluene; $\mathrm{CHN}=$ cyclohexanone; $V_{\mathrm{p}}=$ pore volume; $F_{\mathrm{s}}=$ solvent fraction $=$ amount of diluents $/($ amount of diluents + monomers $) ;{ }^{*}$ bead diameter $=250 \mu \mathrm{m}$.

The values of $\mathrm{Cl}^{-}$ions capacity obtained for $30 \%$ and $50 \%$ cross-linked copolymers were $2.02 \pm 0.14 \mathrm{meq} \mathrm{g}^{-1}$ and $1.28 \pm 0.14 \mathrm{meq} \mathrm{g}^{-1}$, respectively (Table I). These results are in agreement with the previously reported results for 4-vinylpyridine-divinylbenzene ${ }^{15}$ and 2-vinylpyridine-divinylbenzene ${ }^{16}$ copolymers. They are in accordance with the fact that relatively low cross-linked copolymer swells and hence the active-sites become more accessible.

\section{Effect of the Amount of Diluents}

Two sets of polymerization experiments were carried out in a mixture of diluents, CHN: TOL $(40: 60)$ by varying the solvent fraction of the organic phase, $F_{\mathrm{s}}$ from 0.3 to 0.8 . In one set of experiments $30 \%$ while in another $50 \%$ cross-linked copolymer beads were synthesized. The results are summarized in Table II. The apparent density decreases from 0.50 to $0.13 \mathrm{~g} \mathrm{ml}^{-1}$ and 0.53 to $0.22 \mathrm{~g} \mathrm{ml}^{-1}$ for $30 \%$ and $50 \%$ cross-linked copolymer beads, respectively with the increase in $F_{\mathrm{s}}$ from 0.3 to 0.8 . On the other hand the porosity, $V_{\mathrm{p}}$ increases from 0.49 to $3.08 \mathrm{ml} \mathrm{g}^{-1}$ and 0.17 to $1.73 \mathrm{mlg}^{-1}$ for $30 \%$ and $50 \%$ cross-linked copolymer beads, respectively, with the increase in $F_{\mathrm{s}}$ from 0.3 to 0.8 (Table II). These results of apparent density and porosity are complimentary to one another in a way as the apparent density decreases with 


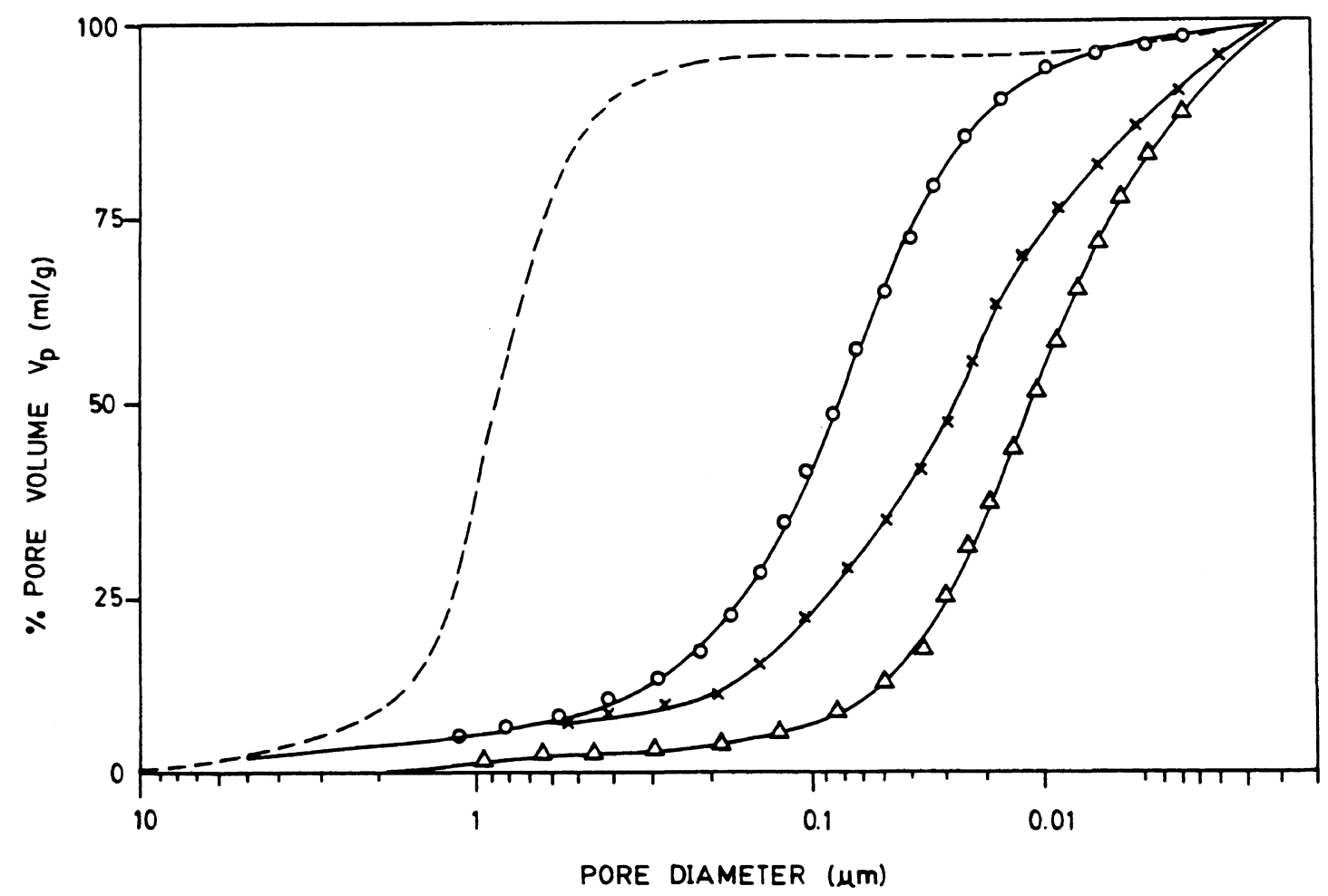

Figure 3. The dependence of pore volume $(\%)$ on pore diameter $(\mu \mathrm{m})$ of $4 \mathrm{VP}-\mathrm{EGDM}$ copolymer beads synthesized in the diluents CHN and TOL $(40: 60)$ and at different solvent fractions, $F_{\mathrm{s}}$ as compared to monomers (pore size distribution curve). Solvent fraction, $F_{\mathrm{s}}(\mathrm{cross}-\mathrm{linkage}=30 \%)$ : ,$-- 0.8 ;-\bigcirc-\mathrm{O}-\mathrm{O}-, 0.6 ;-\times-\times-\times-, 0.5 ;-\triangle-\triangle-\triangle-, 0.4$.

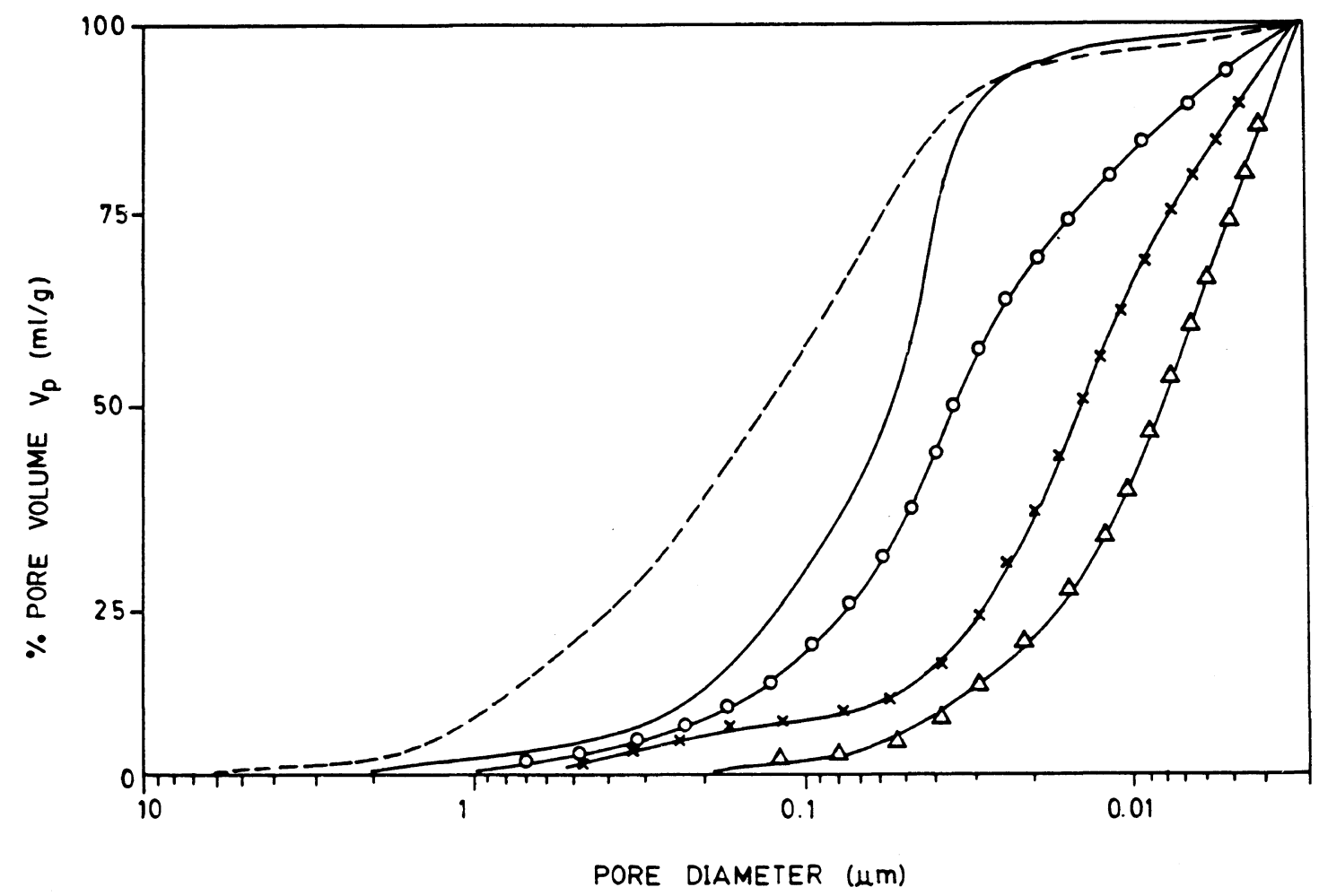

Figure 4. The dependence of pore volume $(\%)$ on pore diameter $(\mu \mathrm{m})$ of $4 \mathrm{VP}-\mathrm{EGDM}$ copolymer beads synthesized in the diluents CHN and TOL $(40: 60)$ and at different solvent fractions, $F_{\mathrm{s}}$ as compared to monomers (pore size distribution curve). Solvent fraction, $F_{\mathrm{s}}(\mathrm{cross}-\mathrm{linkage}=50 \%$ ): ,$--- 0.8 ;-, 0.7 ;-\bigcirc-O-\bigcirc-, 0.6 ;-\times-\times-\times-, 0.4 ;-\triangle-\triangle-\triangle-, 0.3$.

the increase in the porosity of the given copolymer beads. It is also worthwhile to mention here that the values of density are relatively high and the porosity are low in case of $50 \%$ cross-linked copolymer beads as compared to $30 \%$. These results indicate that the dense mesh structures are developed in relatively high cross-linked copolymers. The surface area increases from 47.5 to $235.1 \mathrm{~m}^{2} \mathrm{~g}^{-1}$ and 11.2 to $150.4 \mathrm{~m}^{2} \mathrm{~g}^{-1}$ for $30 \%$ and $50 \%$ cross-linked copolymer beads, respectively, with the increase in $F_{\mathrm{s}}$ from 0.3 to 0.8 . The results of surface area 


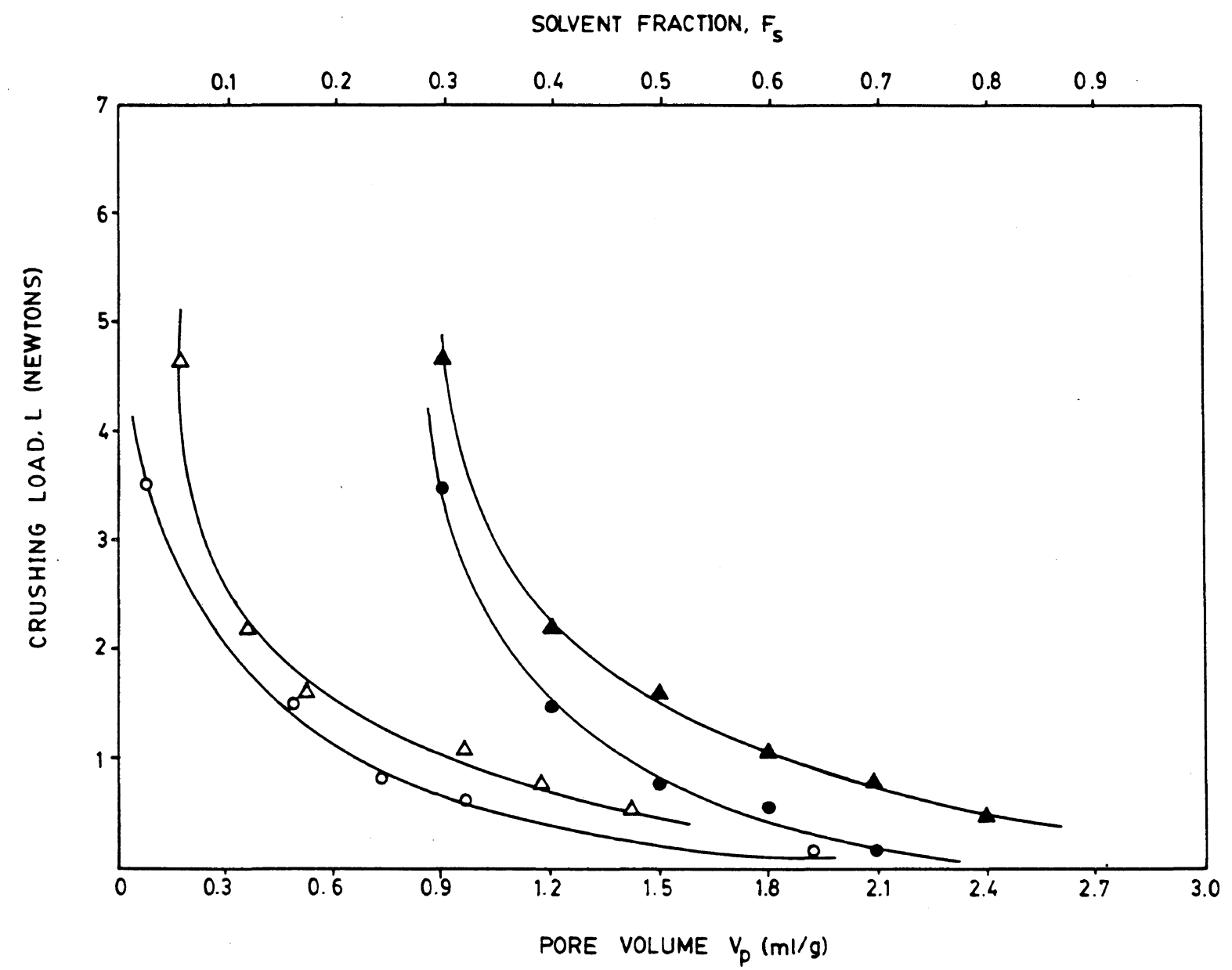

Figure 5. (i) The dependence of crushing load, $L$ (Newtons) on the pore volume, $V_{\mathrm{p}}\left(\mathrm{ml} \mathrm{g}^{-1}\right)$. Diameter of copolymer beads $=250 \mu \mathrm{m}$ and the percentage ratio of diluents $\mathrm{CHN}$ : TOL $=40: 60,-\mathrm{O}-\mathrm{O}-\mathrm{O}-, 30 \%$ cross-linked copolymer beads; $-\triangle-\triangle-\triangle-, 50 \%$ cross-linked copolymer beads. (ii) The dependence of crushing load, $L$ (Newtons) on the solvent fraction, $F_{\mathrm{s}}$. Diameter of copolymer beads $=250 \mu \mathrm{m}$ and the percentage ratio of diluents $\mathrm{CHN}: \mathrm{TOL}=40: 60$. $-\longrightarrow-30 \%$ cross-linked copolymer beads; $-\boldsymbol{\Delta}-\boldsymbol{\Delta}-\boldsymbol{\Delta}-, 50 \%$ cross-linked copolymer beads.

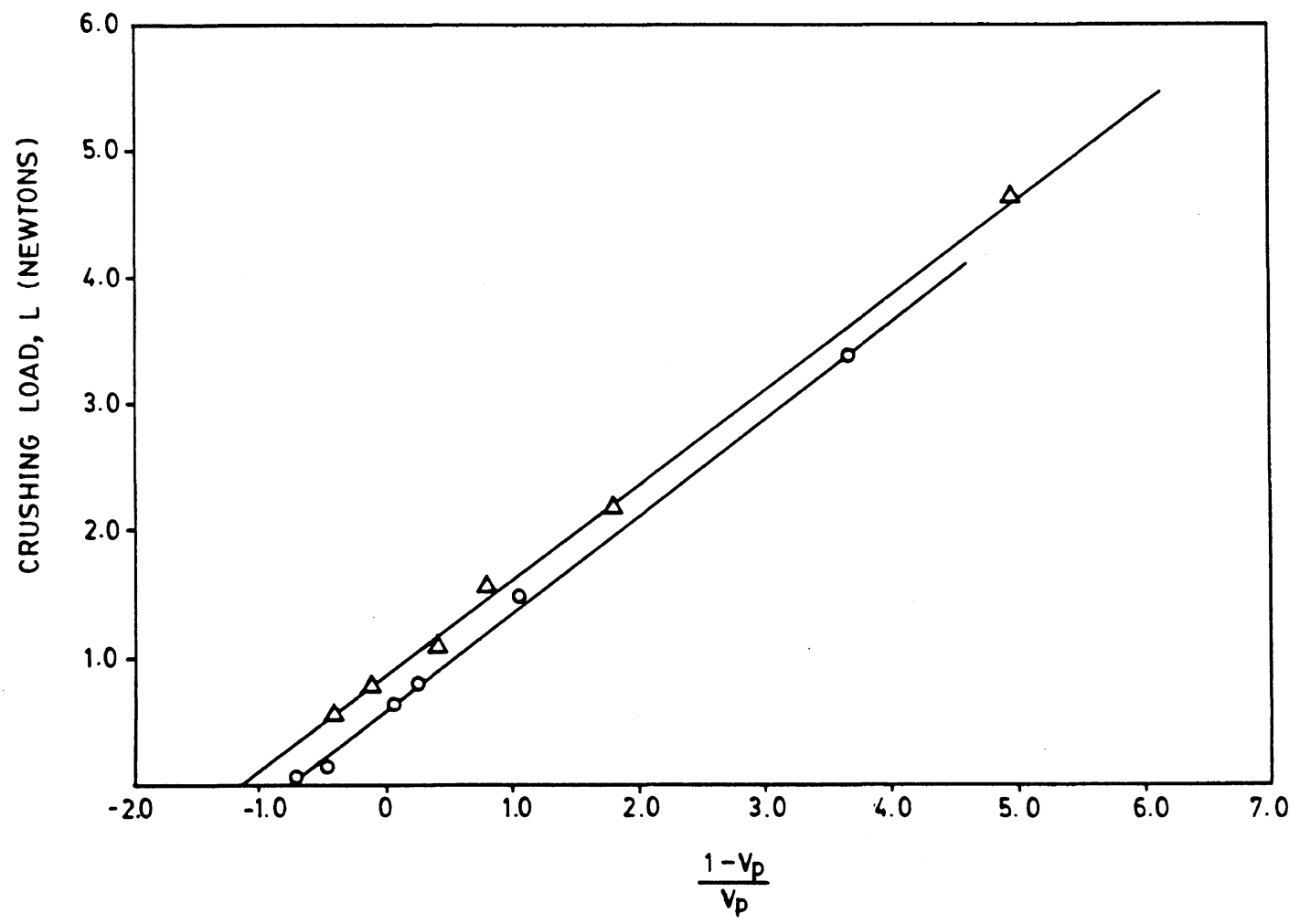

Figure 6. The dependence of crushing load, $L$ (Newtons) on $1-V_{\mathrm{p}} / V_{\mathrm{p}}$. Diameter of the copolymer beads $=250 \mu \mathrm{m}$ and percentage ratio of diluents $\mathrm{CHN}: \mathrm{TOL}=40: 60$. Cross-linkage $=\mathrm{EGDM}:-\triangle-\triangle-\triangle-, 50 \% ;-\mathrm{O}-\mathrm{O}-\mathrm{O}-, 30 \%$. 
Table III. Capacity, porosity, surface area, and density of the 4VP-EGDM copolymers, synthesized using different amount of EGDM ${ }^{\mathrm{a}}$ $\left(F_{\mathrm{s}}=0.5, \mathrm{CHN}: \mathrm{TOL}=40: 60\right)$

\begin{tabular}{|c|c|c|c|c|c|}
\hline \multirow{2}{*}{ Ref. no. } & $\mathrm{X}$-Link & Apparent density & Capacity & Porosity " $V_{\mathrm{p}}$ " & Surface area \\
\hline & $\%$ & $\mathrm{~g} \mathrm{ml}^{-1}$ & meq $g^{-1}$ & $\mathrm{mlg}^{-1}$ & $\mathrm{~m}^{2} \mathrm{~g}^{-1}$ \\
\hline A1909MAH & 10 & 0.10 & 2.89 & 2.16 & 188.0 \\
\hline A2410MAH & 20 & 0.19 & 2.80 & 0.94 & 142.2 \\
\hline A0207MAH & 30 & 0.30 & 1.88 & 0.74 & 130.1 \\
\hline B2310MAH & 40 & 0.36 & 1.35 & 0.56 & 121.7 \\
\hline A0809MAH & 50 & 0.38 & 1.20 & 0.52 & 103.0 \\
\hline
\end{tabular}

a $4 \mathrm{VP}=4$-vinylpyridine; $\mathrm{EGDM}=$ ethylene glycol dimethacrylate; $\mathrm{TOL}=$ toluene; $\mathrm{CHN}=$ cyclohexanone; $V_{\mathrm{p}}=$ pore volume; $F_{\mathrm{s}}=$ solvent fraction $=$ amount of diluents/(amount of diluents + monomers); X-Link =EGDM.

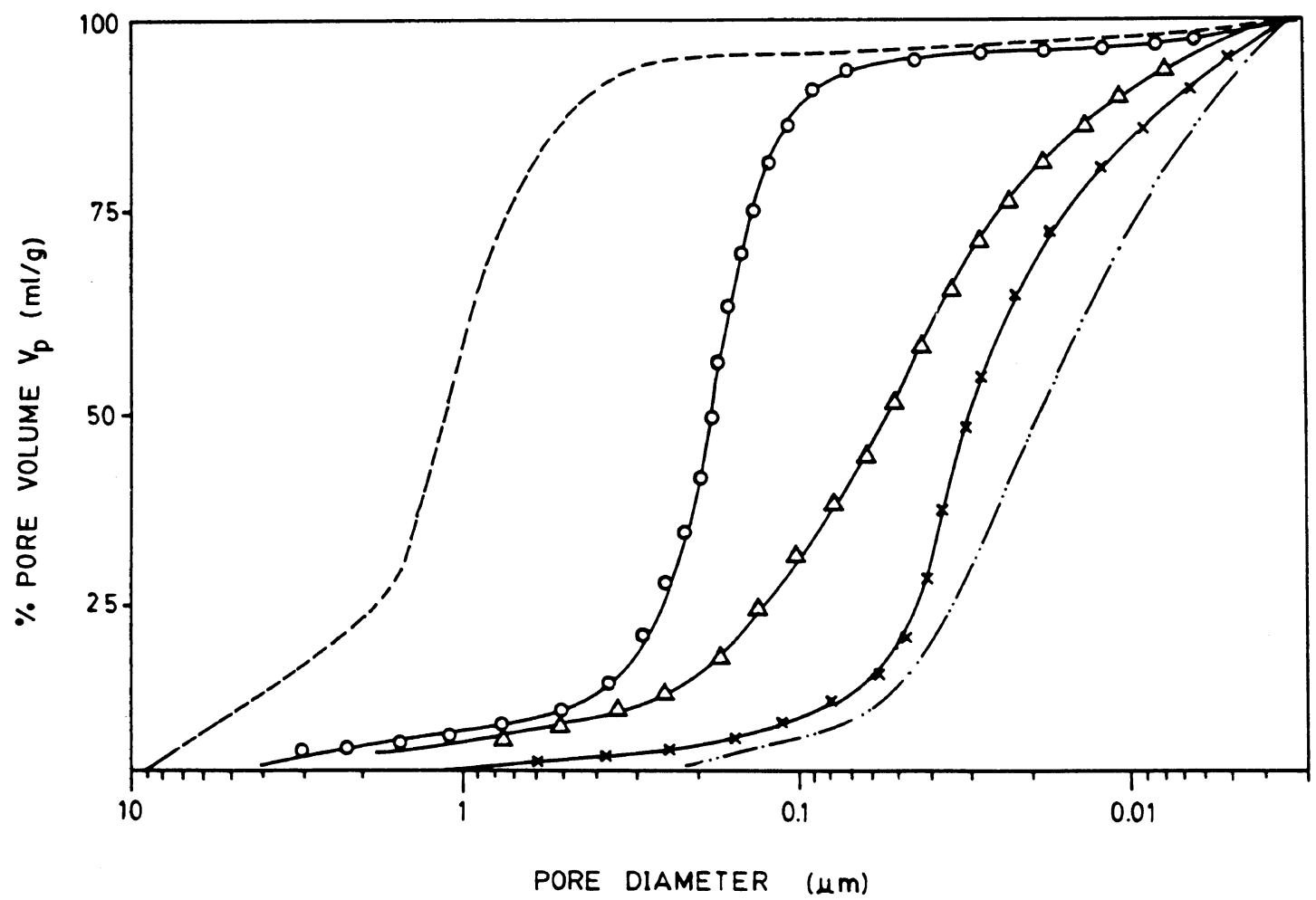

Figure 7. The dependence of pore volume (\%) on pore diameter $(\mu \mathrm{m})$ of $4 \mathrm{VP}-\mathrm{EGDM}$ copolymer beads synthesized in the diluents CHN and TOL $(40: 60)$ at cross-linking agent (EGDM) varying from 10 to $50 \%$ (pore distribution curve). Cross-linking agent (EGDM):,$-- 10 \%$; $-\mathrm{O}-\mathrm{O}-\mathrm{O}-20 \% ;-\triangle-\triangle-\triangle-, 30 \% ;-\times-\times-\times-, 40 \% ;-\cdots--, 50 \%$.

and porosity are in agreement with one another and are in accordance with the expectations.

Figure 3 shows the pore size distribution curves of the $30 \%$ cross-linked copolymer beads when the solvent fraction, $F_{\mathrm{s}}$ was varied from 0.4 to 0.8 . The pore size distribution curves tend to shift towards larger pore size region with the increase in $F_{\mathrm{s}}$ from 0.4 to 0.8 . The shift is very distinct at $F_{\mathrm{s}} 0.8$ and the pore diameter of the beads varies from 0.5 to $2 \mu \mathrm{m}$. Figure 4 shows the pore size distribution curves of the $50 \%$ cross-linked copolymer beads when the $F_{\mathrm{s}}$ was varied from 0.3 to 0.8 . These curves also tend to shift towards larger pore size region with the increase in $F_{\mathrm{s}}$ but the shift is relatively small as compared to that of $30 \%$ cross-linked copolymer beads. These results are in good agreement with those reported for 4-vinylpyridine-divinylbenzene system. ${ }^{15}$

The results of the $\mathrm{Cl}^{-}$ions capacity of copolymers do not seem to reflect a significant change with respect to solvent fraction, $F_{\mathrm{s}}$ used in the given set of polymerization 1058 experiments (Table II). It is however, worth mentioning here that the $\mathrm{Cl}^{-}$ions capacity is almost double in the case of $30 \%$ cross-linked copolymers as compared to those of $50 \%$. This difference in capacity is most probably due to the facts that active sites are more accessible on swelling and the presence of less non functional groups (EGDM) in relatively low cross-linked copolymers. Similar results have also been reported in the literature for $4 \mathrm{VP}-\mathrm{DVB}^{15}$ and $2 \mathrm{VP}-\mathrm{DVB}{ }^{16}$ systems.

The mechanical strength of copolymer beads of $250 \mu \mathrm{m}$ diameter was determined by using the bead crusher apparatus constructed in our laboratory ${ }^{17}$ similar to that used by Golden and Irving. ${ }^{13}$ Figure 5 shows the dependence of crushing load, $L$ (Newtons) on the pore volume, $V_{\mathrm{p}}\left(\mathrm{ml} \mathrm{g}^{-1}\right) /$ solvent fraction, $F_{\mathrm{s}}$ of the $30 \%$ and $50 \%$ cross-linked copolmer beads synthesized in a mixture of diluents (CHN : TOL) 40:60. The curves indicate that the crushing load decreases asymptotically with the increase both in solvent fraction and pore 
volume. These results support the idea that the copolymer beads of relatively small pore volume possesses better mechanical strength and vice versa. The results are in good agreement with those reported in the literature for $N$-vinylcarbazole-DVB system. ${ }^{17}$

Figure 6 shows the dependence of crushing load, $L$ on $\left(1-V_{\mathrm{p}}\right) / V_{\mathrm{p}}$. The resulting straight lines confirm the validity of a modified relationship of different characteristics of porous copolymer beads reported in the previous paper. $^{17}$

Effect of the Amount of Ethylene Glycol Dimethacrylate

A series of polymerization experiments were carried out by varying the amount of cross-linking agent, EGDM from 10 to $50 \%$ in a given mixture of diluents $(\mathrm{CHN}$ : TOL; $40: 60)$ and solvent fraction $\left(F_{\mathrm{s}}=0.5\right)$. The copolymers thus synthesized were characterized. The results are presented in Table III. It was observed that the apparent density of the copolymers increases whereas the $\mathrm{Cl}^{-}$ions capacity, porosity, and surface area decrease with the increase in the cross-linking agent from 10 to $50 \%$. These results are in good agreement with those reported for $4 \mathrm{VP}-\mathrm{DVB}$ system ${ }^{15}$ but disagree with those reported for $N$-vinylcarbazole-DVB ${ }^{17}$ and styrene-DVB systems. ${ }^{18,19}$ This difference of 4VP-EGDM system from the others could be due to the polarity which exists amongst the monomers.

Figure 7 shows the pore size distribution curves of the copolymers with respect to the percentage cross-linking agent. The analysis of these curves suggests that the pore size distribution curves tend to shift from smaller to larger pore size region with the decrease in percentage crosslinkage from 50 to $10 \%$. It seems as if an increase in EGDM changes the polarity of the system. Therefore, EGDM behaves as a crosslinking agent as well as a non-solvating diluent. These two counter effects make the polymerization system relatively more complex to explain but it can be said tentatively that the polarity of the system is decreased due to increase in the crosslinking agent. These results are in good agreement with those reported and discussed in the above mentioned sections for $30 \%$ and $50 \%$ cross-linked copolymers.

In the end it can be concluded on the basis of the results that a resin of controlled pore structure, better mechanical strength, and fast exchange kinetics can be synthesized by using suitable percentage ratio of diluents, solvant fraction with respect to monomers, and desired ratio of monomers under the given experimental conditions.

Acknowledgment. The authors are grateful to $\mathrm{Mr}$. Ejaz ur Rehman for his help to determine the surface area of the copolymer beads and for preparation of the manuscript.

\section{REFERENCES}

1. A. Sugii, M. Nakayama, K. Harada, K. Nishimura, S. Masuda, and K. Takeda, "Preparation and Application of Macroreticular $N$-Methylpyridinium Resin Cross-Linked with Ethylene Glycol Dimethacrylate," New Developments in Ion-Exchange, Proceedings of the International Conference on Ion-exchange, ICIE, 91, Tokyo, Japan, Oct. 2-4, 1991.

2. O. Mikes, Int. J. Pept. Protein Res., 14, 393 (1979).

3. K. J. Wilson, E. Van Wieringen, S. Klauser, M. W. Berchtold, and G. J. Hughes, J. Chromatogr., 237, 407 (1982).

4. R. V. Lewis, A. Fallon, S. Stein, K. D. Gibson, and S. Udenfriend Anal. Biochem., 104, 153 (1980).

5. G. Vanecek and F. E. Regnier, Anal. Biochem., 121, 156 (1982).

6. J. K. Duncan, A. J. C. Chen, and C. J. Siebert, J. Chromatogr., 397, 3 (1987).

7. A. Sugii, K. Harada, K. Nishimura, R. Hanaoka, and S. Masuda, J. Chromatogr., 472, 357 (1989).

8. Y. Kato, K. Nakamura, and T. Hashimoto, J. Chromatogr., 294, 207 (1984).

9. Y. Kato, K. Nakamura, and T. Hashimoto, J. Chromatogr., 266, 385 (1983).

10. T. Kadoya, T. Isobe, Y. Amano, Y. Kato, K. Nakamura, and T. Okuyama, J. Liquid Chromatogr., 8, 635 (1985).

11. M. Marhol, in "Comprehensive Analytical Chemistry," G. Svehle, Ed., "Ion-Exchangers in Analytical Chemistry, Their Properties and Uses in Inorganic Chemistry," Vol. XIV, Elsevier Scientific Publishing Company, Oxford, 1982, pp. 99.

12. S. Brunaner, L. S. Demming, W. S. Demming, and E. Teller, $J$. Am. Chem. Soc., 62, 1723 (1940).

13. L. S. Golden and J. Irving, Chemistry and Industry, Nov. 4, 837 (1972).

14. A. Guyot and M. Bartholin, Prog. Polym. Sci., 8, 277 (1982).

15. M. A. Hamid, M. A. Malik, R. Naheed, and M. Fuzail, Proc. Pak. Acad. Sci., 32 (No. 1-4), 41 (1995).

16. F. M. B. Coutinho, M. I. N. Wiqueira, and C. R. Barbosa, Eur Polym. J., 26, 1189 (1990)

17. M. A. Hamid, R. Naheed, and E. Rehman, to be published in The Nucleus, 33 (No. 3, 4) (1996).

18. H. Jacobelli, M. Bartholin, and A. Guyota, J. Appl. Polym. Sci., 23, 927 (1979).

19. F. M. B. Coutinho and R. C. A. Cid, Eur. Polym. J., 26, 1185 (1990). 